\title{
Options for the management of antiviral resistance during hepatitis $B$ therapy: reflections on battles over a decade
}

\author{
Hyung Joon Yim ${ }^{1,3}$ and Seong Gyu Hwang ${ }^{2,3}$ \\ 'Department of Internal Medicine, Korea University College of Medicine, Seoul; 'Department of Internal Medicine, CHA University \\ School of Medicine, Seongnam, Korea; ${ }^{3}$ Antiviral Resistance Study Group
}

Although much advancement has been achieved in the treatment of chronic hepatitis $B$, antiviral resistance is still a challenging issue. Previous generation antiviral agents have already developed resistance in a number of patients, and it is still being used especially in resource limited countries. Once antiviral resistance occurs, it predisposes to subsequent resistance, resulting in multidrug resistance. Therefore, prevention of initial antiviral resistance is the most important strategy, and appropriate choice and modification of therapy would be the cornerstone in avoiding treatment failures. Until now, management of antiviral resistance has been evolving from sequential therapy to combination therapy. In the era of tenofovir, the paradigm shifts again, and we have to decide when to switch and when to combine on the basis of newly emerging clinical data. We expect future eradication of chronic hepatitis B virus infection by proper prevention and optimal management of antiviral resistance. (Clin Mol Hepatol 2013;19:195-209)

Keywords: Antiviral resistance; Chronic hepatitis B; Hepatitis B virus; Treatment; Nucleoside analogue; Nucleotide analogue

\section{INTRODUCTION}

The mainstay in treatment of chronic hepatitis B virus (HBV) infection is nucleos(t)ide analogues currently. ${ }^{1-4}$ Although nucleos(t) ide analogues are effective in suppressing viral replication, HBV is usually not eradicated with short term therapies, and prolonged therapy is commonly needed. ${ }^{5}$ During the long term therapy, HBV develops resistance to the drug being administered. The resistance rates are higher with earlier generation of nucleos(t)ide analogues such as lamivudine, telbivudine, clevudine, and adefovir. ${ }^{1-3} \mathrm{Al}-$ though entecavir and tenofovir are associated with low risk of resistance for treatment naive patients, it is still difficult to manage preexisting antiviral resistance due to the presence of cross resistance. ${ }^{6}$ Furthermore, multidrug resistance, which had occurred during sequential monotherapy with low genetic barrier drugs, became a serious problem. ${ }^{7}$ To overcome and prevent antiviral resistance during treatment of chronic hepatitis B (CHB), understanding the mechanism, diagnosis, and principles of treatment is

\section{Abbreviations:}

ADV, adefovir; cccDNA, covalently closed circular DNA; CHB, chronic hepatitis B; CLV, clevudine; ETV, entecavir; HBV, hepatitis B virus; LAM, lamivudine; LDT, telbivudine; NA, nucleoside analogues; rt, reverse transcriptase; TDF, tenofovir

\author{
Co-corresponding author : \\ Hyung Joon Yim \\ Department of Internal Medicine, Korea University Ansan Hospital, 123 \\ Jeokgeum-ro, Danwon-gu, Ansan 425-707, Korea \\ Tel. +82-31-412-6565, Fax. +82-31-412-5582 \\ E-mail; gudwns21@medimail.co.kr
}

\section{Seong Gyu Hwang}

Department of Internal Medicine, CHA Bundang Medical Center,

59 Yatap-ro, Bundang-gu, Seongnam 463-712, Korea

Tel. +82-31-780-5213, Fax. +82-2-780-5246

E-mail; sghwang@cha.ac.kr

Received : Jul. 31, 2013/ Accepted : Aug. 18, 2013 
necessary. Herein, we will summarize knowledge about antiviral resistance which has been accumulated over a decade in the field of hepatitis B, and its clinical applications.

\section{Mechanism of antiviral resistance}

Several factors influence on the development of antiviral resistance. Viral (high frequency of spontaneous mutation, viral replication fitness), drug (antiviral potency, genetic barrier), and patient (replication space and other clinical factors) factors interact, and resistance develops more commonly with increasing number of such risk factors. Detailed descriptions of each factor are as follows.

\section{Spontaneous mutation of HBV}

The rate of production of virion is considerably high, estimating up to $10^{11}$ virions per day. ${ }^{8}$ As the size of HBV is approximately 3.2 $\mathrm{kb}$, more than $10^{14}$ nucleotides can be produced per day. However, HBV reverse transcriptase does not have proofreading or editing activity; so, it is prone to develop errors during replication. ${ }^{9}$ The error rate of $\mathrm{HBV}$ has been calculated as $10^{-7}$ per nucleotide per day. ${ }^{8}$ Therefore, $10^{7}$ base pairing errors are produced daily. These high spontaneous mutation rates primarily predispose to antiviral resistant mutations. ${ }^{10}$

\section{Replication fitness under selection pressure}

Various mutations developed during replication are archived in the reservoir. Under the selection pressure exerted by antiviral drug or immunologic response, specific quasispecies which show the best replication fitness are selected. Replication fitness is ability to produce offspring under selection pressure exerted by antiviral agents. ${ }^{11}$ Viral quasispecies with maximal fold resistance (ratio of drug concentration needed to suppress mutant virus by $50 \%$ over drug concentration needed to suppress wild type virus by $50 \%$, i.e. mutant $I C_{50} /$ wild type $\left.I C_{50}\right)$ to antiviral drugs being administered and high replication capacity retain the best replication fitness, which gives chance to be selected as a primary drug resistant mutant. Sometimes, compensatory mutations developed secondary to primary drug resistant mutations recover replication capacity of the mutant virus over that of wild type virus. ${ }^{12}$

\section{Antiviral potency}

The probability of developing drug resistant mutation during therapy depends on the efficacy of drug. ${ }^{13}$ With the potent antiviral agents, complete suppression of viral replication allows little opportunity for occurrence of resistance because mutation is replication dependent. ${ }^{14}$ If the potency of antiviral agent is low, there is low selection pressure, so the chance of developing resistance is still low. However, antiviral agents with intermediate potency suppress viral replication incompletely, and the selection pressure is higher than low-potency drug. Therefore the chance of developing resistance is the highest under drugs with modest potency. ${ }^{14}$ Other factors associated with antiviral agent include pharmacodynamic properties that reflect how quickly the HBV viral load is reduced on treatment and pharmacokinetic properties if the drug may or may not be able to reach sequestered site or sanctuaries of viral replication; i.e. reduction of cccDNA. ${ }^{9,15}$

\section{Genetic barrier}

Genetic barrier is the number of mutations needed to exhibit resistance to the antiviral drug being administered. ${ }^{13}$ A drug which needs multiple site mutations on viral genome for developing resistance has a high genetic barrier and the resistance rate is low. ${ }^{16}$ Also, combination of two drugs can lead to increase of genetic barrier. ${ }^{17}$

\section{Replication space}

Replication space for HBV means the potential space of the liver to accommodate new transcriptional templates or molecules of cccDNA. ${ }^{18}$ Hepatocyte turn over in the normal liver is relatively slow, presumably more than 100 days. However, in the setting of severe necroinflammatory activity, this may reduced to less than 10 days. $^{8}$ Increased turnover rates of hepatocyte result in generation of new replication space uninfected by wild type virus. Mutant virus will more easily take over new replication space by virtue of higher replication fitness. In the setting of liver transplantation, large amount of new replication space will be provided for mutant virus if drug resistance develops. Hence, rapid spread of mutant virus in uninfected hepatocyte is expected occupying new replication space. ${ }^{19}$

\section{Other clinical factors}

Clinical factors, especially associated with patient's medical history, are prior drug experience, compliance of patients, and host genetic factors such as ability to efficiently convert the agent to its active metabolite. ${ }^{9,15}$ Previous exposure to an antiviral agent may predispose to development of resistance. In some case, effective drug concentration may not be achieved due to poor compliance or intrinsic enzymatic defect. ${ }^{9}$ Poor antiviral effects lead to selection of drug resistant strains. So, when the viral suppression is in- 

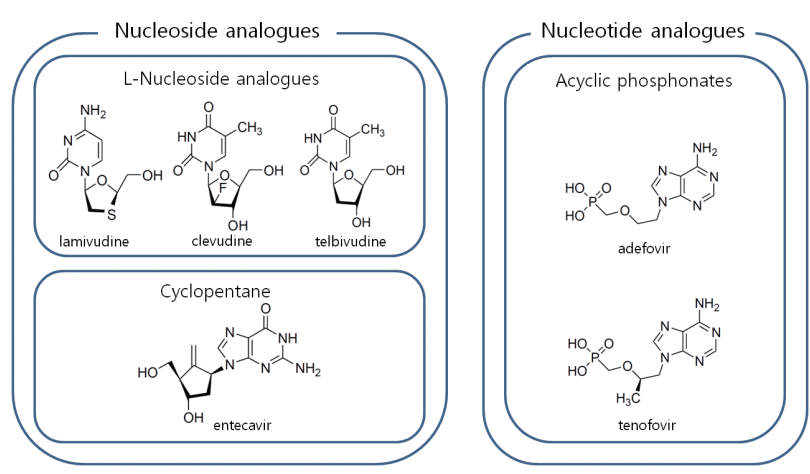

Figure 1. Classification of antiviral agents for treatment of chronic hepatitis B. To manage antiviral resistance, one drug from nucleoside analogues and another from nucleotide analogues are selected for combination.

sufficient, clinical factors should be reviewed.

\section{Molecular changes causing antiviral resistance}

Antiviral agents for the treatment of HBV infection are classified into two groups; nucleoside analogues and nucleotide analogues. Cyclopentane (entecavir) and L-nucleoside analogues (lamivudine, telbivudine, clevudine) belong to nucleoside analogues and acyclic phosphonates (adefovir, tenofovir) belong to nucleotide analogues (Fig. 1).

\section{Resistance to nucleoside analogues}

\section{L-nucleoside analogues}

rtM204V/I, the major lamivudine resistant mutation, is located in the domain $C$ at catalytic YMDD motif. Additional mutations are noted as compensatory mutations that enhance the replication capacity. These include rtL80I/V, rtV173L, rtL180M, rtT184S, rtA200V, rtQ2155. ${ }^{6,20}$ Although rtM204I can be found in isolation, rtM204V is usually found with compensatory mutations, most commonly rtL180M. Major resistance mutation to telbivudine or clevudine is rtM204I. ${ }^{6}$ In clevudine-resistant patients, rtL80I/V may be accompanied as a compensatory mutation. ${ }^{21}$ The rtA181T mutation was first detected in a patient receiving lamivudine, but also found in patients being treated with telbivudine, clevudine, adefovir or combination of adefovir and lamivudine. ${ }^{22} \mathrm{rtL} 80 \mathrm{I} / \mathrm{V}$ and rtQ215S also show resistance to adefovir. ${ }^{20}$

\section{Cyclopentane}

Entecavir resistance emerges by two steps. Lamivudine resistance develops first, and then additional changes such as rtM250V/I/L, rtT184L/F/A/M/S/I/C/G or rtS202G///C develop on

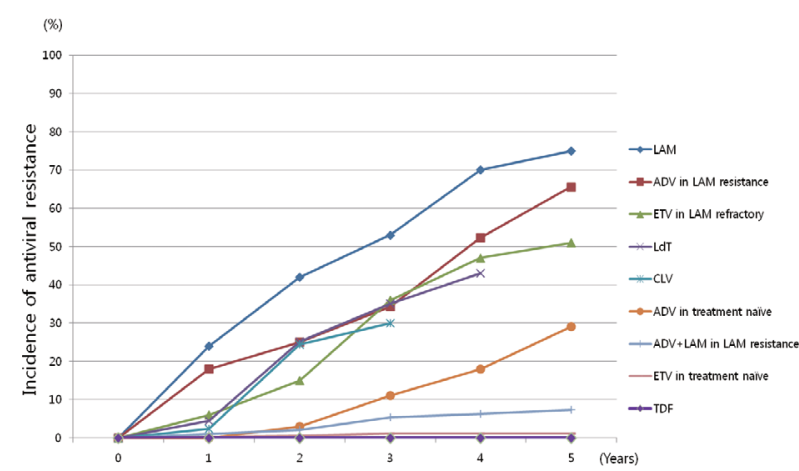

Figure 2. Cumulative incidence of antiviral resistance according to the drugs. ${ }^{1,2,6,20}$ L-nucleoside analogues show high rate of antiviral resistance in treatment naïve patients. Also, adefovir or entecavir monotherapy exhibit high resistance rates in lamivudine refractory patients. LAM, lamivudine; CLV, clevudine; LdT, telbivudine; ETV, entecavir; ADV, adefovir; TDF, tenofovir.

the background of lamivudine resistant mutations (rtL180M+rt$\mathrm{M} 204 \mathrm{~V} / \mathrm{I}){ }^{23}$ It has been reported that these mutations are co-located on the same viral genome. ${ }^{7}$ Without lamivudine resistant mutations, mutations on rtM250, rtT184, or rtS202 by themselves do not exhibit significant resistance to entecavir. Although entecavir resistance is rare in treatment naive patients, ${ }^{16}$ simultaneous development of resistance to entecavir and lamivudine has been reported. ${ }^{24}$

\section{Resistance to nucleotide analogues}

This group includes adefovir and tenofovir. Resistance to adefovir is associated with mutations in the domain D at rtN236T and/ or in the domain B at rtA181V/T. ${ }^{25}$ Several mutations were further detected in adefovir-resistant patients in the absence of rtN236T or rtA181V. These mutations include rtP237H, rtN238T/D, rtV84M, and rtS85A, which are located around rtN236T. ${ }^{20} \mathrm{rtQ} 215 \mathrm{~S}$ and rtV214A are also adefovir resistant mutations. The rtA181T and rtQ215S are cross resistant to lamivudine. ${ }^{20}$

rtA194T, a tenofovir resistant mutation, is located in domain B and was firstly detected in HIV and HBV coinfected patients. ${ }^{26}$ However, tenofovir resistance was not found during clinical trials on $\mathrm{CHB}^{27}$

Cumulative incidences of antiviral resistance according to drugs are illustrated in Figure 2.

\section{Clinical consequences of antiviral resistance and associated definitions}

During treatment of $\mathrm{CHB}$, development of antiviral resistance 
Table 1. In vitro drug susceptibility and cross resistance of antiviral-resistant HBV 1,2,6

\begin{tabular}{|c|c|c|c|c|c|c|c|}
\hline \multirow{2}{*}{ Resistance to } & \multirow{2}{*}{ Mutation } & \multicolumn{6}{|c|}{ Susceptibility } \\
\hline & & LAM & CLV & LDT & ETV & ADV & TDF \\
\hline none & Wild type & $S$ & $S$ & $S$ & $S$ & $S$ & $S$ \\
\hline L-NA & rtL180M+rtM204V/I & $\mathrm{R}$ & $\mathrm{R}$ & $\mathrm{R}$ & । & $S$ & $S$ \\
\hline ETV & $\begin{array}{l}\text { rtL180M+rtM204V/I+rtT184L/F/A/M/S/I/C/G } \\
\text { or rtS202G/I/C or rtM250V }\end{array}$ & $\mathrm{R}$ & $\mathrm{R}$ & $\mathrm{R}$ & $\mathrm{R}$ & $S$ & $S$ \\
\hline L-NA + ADV & rtA181T & $R$ & $\mathrm{R}$ & $\mathrm{R}$ & $S$ & $\mathrm{R}$ & $S$ \\
\hline ADV & rtA181V+rtN236T & । & 1 & । & $S$ & $\mathrm{R}$ & I \\
\hline ADV & rtN236T & S & S & S & S & $\mathrm{R}$ & I \\
\hline TDF & rtA194T & $\mathrm{R}$ & NA & I & S & $\mathrm{R}$ & $\mathrm{R}$ \\
\hline
\end{tabular}

LAM, lamivudine; CLV, clevudine; LDT, telbivudine; ETV, entecavir; ADV, adefovir; TDF, tenofovir; L-NA, L-nucleoside analogues (LAM, LDT, CLV), NA; not available.

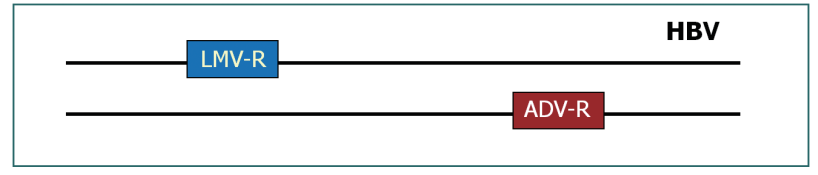

or

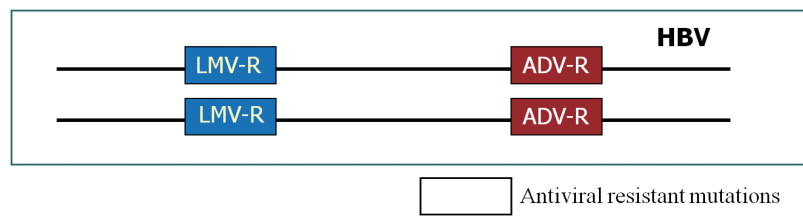

Figure 3. Models of multidrug resistant hepatitis B virus.' (A) mutants are located on different genomes, (B) mutants are located on the same genome. Resistance mutations to different antiviral agents may or may not be located on the same viral genome. A previous study showed that $85 \%$ of mutations are present on the same viral genome. This suggests efficacy of combination therapy will not be effective if drugs previously developed resistance are combined.

begins with mutational changes in the polymerase gene of HBV. Those changes may reduce susceptibility of virus to the drug that is being administered. Genotypic resistance, which is defined as development of mutations conferring resistance to the given antiviral drug, is followed by increase of HBV DNA levels. ${ }^{28}$ When serum HBV DNA level rises over 10 times of the nadir, we consider that viral breakthrough occurred. ${ }^{28}$ If appropriate management is not given at this time, increase of serum alanine aminotransferase may be followed, which is known as biochemical breakthrough. ${ }^{28}$ Clinically, hepatitis flare may occur and hepatic failure and death have been reported in patients with poor hepatic reserve. Therefore, therapy should be modified before clinical deterioration is noted. However, it should be kept in mind that nearly $40 \%$ of CHB patients receiving antiviral therapy may not be fully adherent to the medication. ${ }^{29}$ Therefore compliance needs to be assessed as the first step, and if the patient is adherent to the medication, an- tiviral resistance test should be done promptly.

One of important clinical problems of antiviral resistance is emergence of multidrug resistance. ${ }^{7}$ Multidrug resistance during anti-HBV therapy is defined by the occurrence of resistance to both nucleoside analogues and nucleotide analogues by a strict criterion. This can be caused either by a single genomic mutation or by multiple mutations on the same viral genome. ${ }^{7}$ A single genomic mutation developed by one antiviral agent may show resistance to another drug which has not been exposed before due to "cross resistance" (Table 1). Although cross resistance is commonly present in-between the drugs belonging to the same class (e.g. rtM204I for lamivudine and telbivudine), it can also be present inbetween the drugs belonging to different classes (e.g. rtA181T to both lamivudine and adefovir), which results in multidrug resistance. Multiple resistant mutations to different classes of antiviral agents can be developed on the same viral genome, and show resistance to the both drugs (e.g. rtL180M+rtM204V+rtN236T to both lamivudine and adefovir) (Fig. 3). ${ }^{7}$ Therapy with low genetic barrier drugs enhances the chance of development of multiple mutations, especially when used alone sequentially.

\section{Diagnosis of antiviral resistance}

In the clinical practice, development of virologic breakthrough in a patient who has been compliant with the therapy is the first sign of development of antiviral resistance. To confirm the genotypic resistance, a number of techniques are applicable including direct PCR sequencing, reverse hybridization line-probe assay, restriction fragment length polymorphism analysis (RFLP), restriction fragment mass polymorphism analysis (RFMP), and DNA chip technologies. ${ }^{28}$ Currently ultradeep pyrosequencing assay is available. 
Hyung Joon Yim, et al.

Options for the management of antiviral resistance during hepatitis B therapy

\section{Direct sequencing}

Direct sequencing is one of the most commonly used methods for detecting the presence of resistant mutations. In the clinical trials of new antiviral agents, direct sequencing is adopted for detection of new molecular changes which may confer resistance to the given drug as this assay allows reviewing all the sequences. ${ }^{28}$ However, lack of sensitivity in detecting minor populations of mutants limit the early diagnosis of development of antiviral resistance. Usually, mutant virus population $>20 \%$ among the total HBV quasispecies pool are detectable with this assay. Although cloning can overcome the limitation by increasing number of colonies for analysis, ${ }^{7}$ highly skilled personnel's labor-intensive work is required.

\section{Line-probe assay}

A series of short membrane-bound oligonucleotide probes is used to detect single nucleotide mismatches in PCR-amplified HBV DNA. ${ }^{30}$ Line-probe assay can discriminate a minor fraction of the total viral population as low as $5 \%$. However, specific probes must be prepared for the detection of each mutation of interest in advance. In addition, this assay cannot estimate a mutation frequen$c y$, so it is useful for dynamic studies of viral evolutions.

\section{RFMP analysis}

The assay is based on PCR amplification and mass measurement of oligonucleotide containing specific sites of mutation. ${ }^{31} \mathrm{En}$ zymatic cleavage of the sites leads to multiple DNA fragments, from which matrix-assisted laser desorption/ionization time of flight mass spectrometry (MALDI-TOF MS) differentiates specific mutations as little as $1-5 \%$ of total viral population. ${ }^{31,32}$ With this technique, quantitative detection of mixed populations can be done even without population-based cloning. ${ }^{32}$

\section{RFLP analysis}

Endonucleolytic cleavage of amplified viral DNA using restriction enzymes generate fragment of DNA of varying length of specific sequence with this assay. ${ }^{28}$ Presence of mutation can be differentiated by a different pattern of DNA fragment as some mutations produce a new restriction site while others may delete it. RFLP is a very sensitive to detect variant as little as $5 \%$ of total viral population. However, it is technically difficult to perform and requires high cost. ${ }^{28}$

\section{DNA chip technology}

Sequencing with microchip based technology using oligonucle- otide microarrays has good sensitivity to detect mutants as low as $10 \%$ of total viral population. ${ }^{32}$ The technique is capable of detecting multiple mutations as well as polymorphisms simultaneously. However, it needs to update specific sequence primer according to the reported mutational profile. This is the main drawback of this assay like other methods mentioned above (line probe assay, RFMP, RFLP).

\section{Ultradeep pyrosequencing assay}

Pyrosequencing assay is a new sequencing method which relies on the detection of DNA polymerase activity. ${ }^{33}$ This technique performs massively parallel picoliter-scale amplification and pyrosequencing of individual DNA molecules, enabling the analysis of thousands of clonally amplified regions, which increases the probability of detecting minority of mutants. ${ }^{33}$ Pyrosequencing is currently the most sensitive assay that can detect minor variant populations as low as $0.1 \%$, and considered as the most valuable tool for researching the viral genome in the future.

\section{Management of antiviral resistance: focusing on multidrug resistance}

It has been reported that starting rescue therapies at the low level viremia is more effective than delayed implementation in the presence of virologic breakthrough and confirmed genotypic resistance. Therefore rescue therapy should not be delayed after the diagnosis of antiviral resistance to enhance to the efficacy of therapy and to decrease the risk of clinical deterioration.

Choice of rescue therapy for the antiviral resistant CHB is based on cross resistance profile of antiviral drugs; a drug without cross resistance to the prior antiviral agent should be selected. To ensure the absence of cross resistance, results of the resistance test should be referred.

However, even a drug without cross resistance may not be sufficient for long term treatment as subsequent resistant mutations can arise during monotherapy with a low genetic barrier drug, resulting in multidrug resistance as described above. Therefore, combination of drugs that belong to different class should be considered paring one from nucleoside analogues and the other from nucleotide analogues.

In any cases with nucleos(t)ide resistant $\mathrm{CHB}$, interferon-based therapy should be considered if the patients have compensated liver function. Although, the efficacy is still not satisfactory, it would be reasonable to challenge to avoid occurrence of multidrug resistance following multiple treatment failure of nucleos( $(t)$ 
ide analogues. ${ }^{34}$

Although many guidelines from Korean and the major international liver associations have suggested recommendations for managing antiviral resistant CHB (Table 2), more detailed discussions are necessary as new data are emerging and the paradigm is shifting.

\section{Lamivudine resistance; a principal source of multidrug resistance}

Resistance to lamivudine increases over time up to 70\%. High baseline viral load and ALT, and incomplete viral suppression during therapy increase the risk of lamivudine resistance. ${ }^{35}$ Treatment to lamivudine resistance is based on tenofovir or adefovir, and can be suggested as follows.

- Preferred options for the treatment of lamivudine resistance

1) rtM204V/I mutation

- Tenofovir monotherapy

- Tenofovir plus one of L-nucleoside analogues

- Adefovir plus one of nucleoside analogues

2) rtA181T mutation

- Tenofovir plus one of nucleoside analogues

- Adefovir plus entecavir

Tenofovir is a nucleotide analogue and does not show cross resistance to nucleoside analogues such as lamivudine, telbivudine, clevudine, and entecavir. Tenofovir suppressed HBV DNA more potently in the HBeAg positive or negative subjects compared with adefovir in phase 3 clinical trials. Seventy six percent of $\mathrm{HBeAg}$ positive CHB patients and $93 \%$ of $\mathrm{HBeAg}$ negative patients achieved undetectable HBV DNA by PCR (<400 copies $/ \mathrm{mL}$ ). Although this trial included only small proportion of patients with lamivudine experience, nearly all of the patients achieved virologic response without development of resistance up to 6 years. ${ }^{27}$ It was also reported that lamivudine-failed CHB patients equally responded to the tenofovir compared with treatment naïve patients. ${ }^{36}$ Baseline lamivudine resistant mutations included rtL80I/V, rtV173L, rtL180M, rtA181T, and rtM204V in this study, and type of mutation did not significantly affect the virologic response. ${ }^{36}$

Previously, tenofovir was demonstrated to have superior efficacy compared with adefovir in CHB patients with lamivudine resistance. ${ }^{37}$ In a retrospective study with 53 lamivudine resistant CHB patients, HBV DNA was suppressed to $<400$ copies $/ \mathrm{mL}$ in $100 \%$ of tenofovir group compared with only in $44 \%$ of adefovir group after 48 weeks of therapy. Furthermore, a subsequent study re- ported that tenofovir rapidly suppressed HBV DNA to <400 copies $/ \mathrm{mL}$ in $95 \%$ of the patients within a median of 3.5 months in lamivudine resistant patients who showed high HBV DNA level during adefovir therapy. ${ }^{38}$ Therefore, for lamivudine resistant CHB patients, it is considered that tenofovir is an effective antiviral agent and should be considered as the first line treatment option as well as a rescue therapy in adefovir suboptimal responders.

Tenofovir has been administered alone or in combination with L-nucleoside analogues such as lamivudine and emtricitabine in above studies. ${ }^{36,37,39}$ Recently there has been a report that tenofovir monotherapy is as effective as combination of tenofovir and emtricitabine. $^{40}$ In this prospective study, 280 CHB patients with lamivudine resistance were randomly assigned to either tenofovir monotherapy group or combination group. After 96 weeks of treatment, $89 \%$ of monotherapy group and $86 \%$ of combination group showed HBV DNA <400 copies/mL. No tenofovir resistant mutation was detected during the treatment period in both groups. Therefore tenofovir monotherapy is considered as effective as combination of tenofovir and L-nucleoside analogue. In line with these observations, recently updated European Association for the Study of the Liver (EASL) guidelines recommends tenofovir monotherapy as the first option for lamivudine resistant $\mathrm{CHB}$. Also, Asia Pacific Association for the Study of the Liver (APASL) and Korean Association for the Study of the Liver (KASL) recommend tenofovir monotherapy as an option. ${ }^{1,4}$ However, there is still a concern about the occurrence of subsequent resistant mutation after a long term monotherapy. ${ }^{26}$ Therefore, combining a lamivudine or emtricitabine might be a more reliable option. Efficacy of telbivudine combined with tenofovir has been reported as well. ${ }^{41}$ Considering that telbivudine has potential to improve renal function, ${ }^{42}$ this combination needs to be further evaluated.

Adefovir has been used for the management of lamivudine resistance for a long time. However, adefovir resistance was reported in patients with adefovir monotherapy to be $18 \%$ at year 1 and $25 \%$ at year $2 .^{43,44}$ Soon after these reports, a small randomized clinical trial showed benefit of adefovir add-on therapy over switching to adefovir monotherapy in HBeAg negative CHB patients. ${ }^{17}$ Incidence of adefovir resistance was significantly lower in adefovir add-on therapy group than monotherapy group (0\% vs $21 \%$ ). Since then, adefovir has been recommended to be used in combination with lamivudine. Instead of lamivudine, telbivudine can also be used based on a previous report. ${ }^{45}$

Entecavir has antiviral activity against lamivudine resistant HBV strains, ${ }^{46,47}$ but exhibits some cross resistance. ${ }^{6}$ Hence, 1 mg of entecavir was recommended to be used instead of usual dose of 0.5 
Hyung Joon Yim, et al. Options for the management of antiviral resistance during hepatitis $B$ therapy

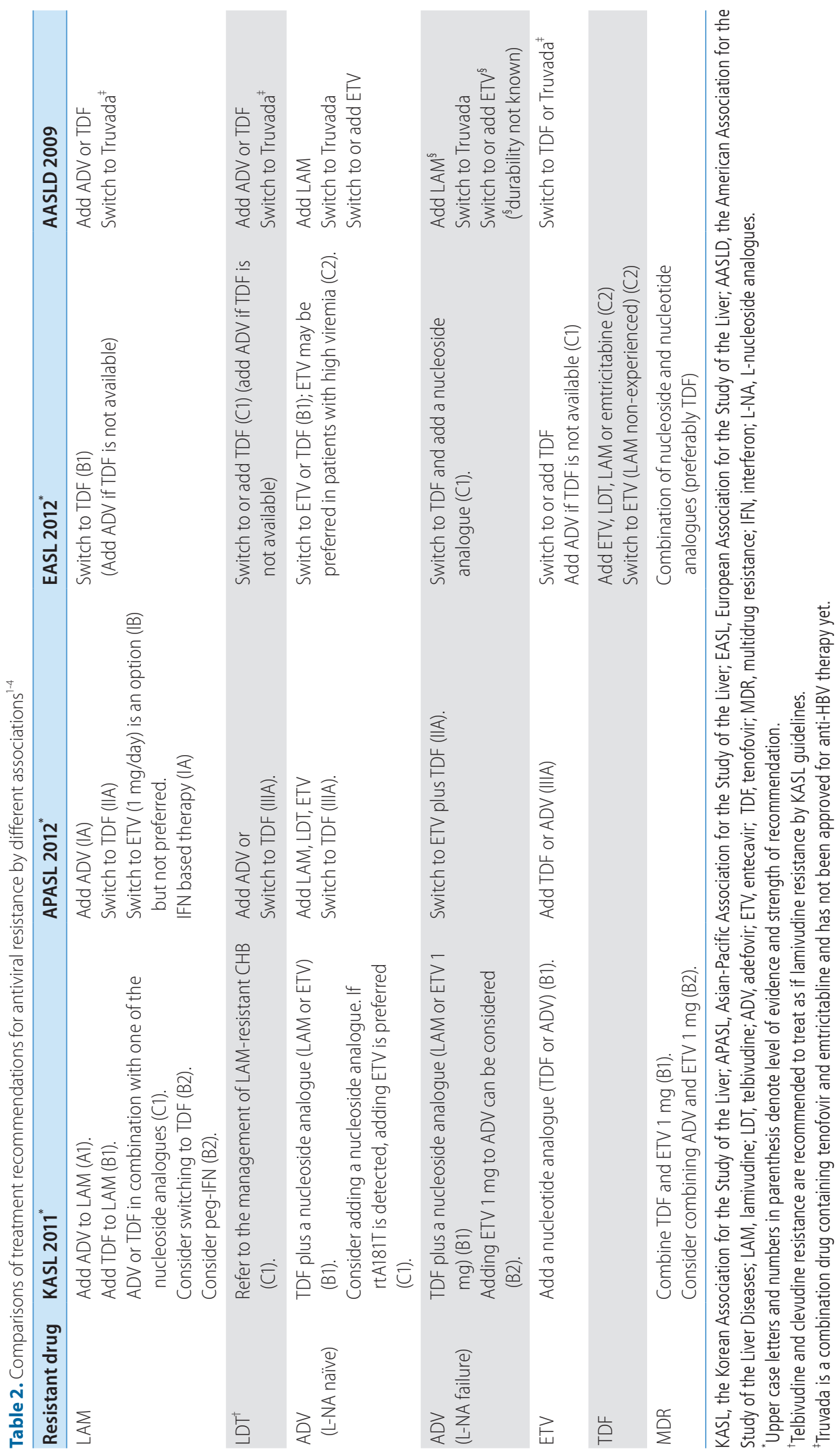


mg. However, long term entecavir monotherapy has been associated with occurrence of entecavir resistant mutations in 51\% and subsequent viral breakthrough in $43 \%$ of lamivudine refractory CHB patients after 5 years. ${ }^{16}$ A prospective randomized trial conducted in Korea have compared combination of adefovir and lamivudine vs. entecavir monotherapy, and showed significant lower incidence of virologic response (56.7\% vs. $40 \%$, respectively) and higher incidence of genotypic resistance combined with viral breakthrough ( $2.0 \%$ vs. $17.6 \%$, respectively) in entecavir monotherapy group after 2 years of treatment. ${ }^{48}$ Therefore entecavir is not considered as an optimal antiviral agent for lamivudine resistant CHB when used alone. More recently, entecavir has been tested in combination with adefovir, and it was superior to entecavir monotherapy or combination of lamivudine and adefovir in HBeAg positive lamivudine resistant CHB patients. ${ }^{49}$ Furthermore, a randomized controlled trial reported that combination of entecavir and adefovir effectively suppressed lamivudine resistant HBV in patients who showed suboptimal response to combination of lamivudine and adefovir. ${ }^{50}$ Also, this combination was effective even in the presence of rtA181T which is a resistant mutation to both lamivudine and adefovir. ${ }^{51}$ Therefore, combination of adefovir and entecavir could be applied in difficult-to-treat lamivudine resistant patients if tenofovir is not available.

Telbivudine or clevudine resistance: cross resistance inbetween nucleoside analogues

- Preferred options for the treatment of telbivudine (or clevudine) resistance

- Refer to the preferred options for the treatment of lamivudine resistance

Although telbivudine is exposed to risk of antiviral resistance during long term therapy, data on the management of telbivudine resistance is limited. ${ }^{52}$ As telbivudine shares almost same resistance profile with lamivudine, it has been proposed to manage telbivudine resistance as if lamivudine resistance. ${ }^{1-3}$ Recently efficacy of telbivudine plus adefovir has been reported to be $74.2 \%$ of virologic response after 12 months of rescue therapy in patients who had confirmed genotypic resistance to telbivudine..$^{53}$ Entecavir plus adefovir therapy was also shown to be effective in patients with telbivudine resistance. ${ }^{54}$ Entecavir plus adefovir therapy would be a better choice than telbivudine plus adefovir, if rtA181T is detected. However, tenofovir with or without combination of Lnucleoside analogues should be the most effective option consid- ering lamivudine resistance data. ${ }^{38}$

Clevudine resistance is considered as the same as telbivudine resistance; rtM204I and rtA181T. Data on the management of clevudine resistance is also still limited. A multicenter study conducted in Korea showed clevudine plus adefovir was superior to other options such as lamivudine plus adefovir, adefovir monotherapy, or entecavir monotherapy. ${ }^{55}$ The efficacy of tenofovir in these patients needs to be evaluated, but it is expected to be as efficacious as in lamivudine resistant CHB patients.

\section{Adefovir resistance with or without resistance to L-nucle-} oside analogues

Resistance to adefovir can be managed by either tenofovir or entecavir based therapies.

- Preferred options for the treatment of adefovir resistance

1) rtN236T mutation

- Tenofovir plus one of nucleoside analogues

- Adefovir plus entecavir* (L-nucleoside analogues may be used in the patients without prior resistance to L-nucleoside analogues)

2) rtA181T/V \pm rtN236T mutations

- Tenofovir plus one of nucleoside analogues

- Adefovir plus entecavir

A randomized trial was conducted to compare the efficacy of tenofovir monotherapy with that of tenofovir plus emtricitabine combination in adefovir-treated CHB patients. ${ }^{56}$ All the patients had been treated with adefovir more than 6 months, but HBV DNA continued to be detected at enrollment. At week 48 , overall $81 \%$ of total patients who were initially given tenofovir $(n=53)$ or tenofovir plus emtricitabine $(n=52)$ had HBV DNA $<400$ copies/ $\mathrm{mL}$. The presence of adefovir resistant mutations did not affect the outcomes. However, in this study, emtricitabine was permitted to be added if HBV DNA was detectable after 24 weeks of tenofovir monotherapy, which may have affected treatment outcomes.

Another prospective study enrolled 60 CHB patients who failed in both lamivudine and adefovir treatment. ${ }^{57}$ Sixty three percent of patients were switched from adefovir to tenofovir monotherapy, and the remainder received tenofovir and lamivudine combination therapy. Patients, who were initially treated with tenofovir monotherapy, switched to tenofovir plus lamivudine after week 24 if persistent viral replication is noted. After 96 weeks of treatment, $64 \%$ of the patients achieved virologic response defined by HBV DNA $<15 \mathrm{IU} / \mathrm{mL}$ (87 copies/mL). The response rate was inferior to 
Hyung Joon Yim, et al.

Options for the management of antiviral resistance during hepatitis B therapy

that observed in treatment naïve patients and in previous studies of tenofovir rescue therapy. Although they reported that the response was independent of baseline mutations conferring resistance to adefovir, there is a possibility that adefovir-resistant mutations have been selected, especially, during monotherapy. Indeed, a study of clonal analysis, which was performed in $10 \mathrm{ad}$ efovir resistant CHB patients with rt236T and/or rtA181T at baseline, showed that adefovir resistant mutations remained detectable throughout the whole observation periods until 72 weeks of tenofovir monotherapy; adding lamivudine led to a virologic response within a few weeks. ${ }^{58}$ Considering these data, adding a nucleoside analogue would be a safer way to prevent selection of resistant mutations. Among nucleoside analogues, entecavir may be the most effective drug as it exhibits the lowest fold changes of inhibitory concentrations in suppressing adefovir-resistant mutants. ${ }^{59}$ An international multicenter cohort study, which included 17 adefovir resistance cases among 57 pre-treated CHB patients, evaluated efficacy of entecavir plus tenofovir combination as a rescue therapy during median 21 months of treatment. ${ }^{60}$ Fifty one of 57 patients became HBV DNA undetectable after a median duration of 6 months. All adefovir resistant patients except one achieved virologic response at month 12. Considering that 5 of 17 adefovir resistant patients also had M204V/I mutation at baseline, this combination is considered to be also effective in treating multidrug resistant $\mathrm{CHB}$.

Before the era of tenofovir or entecavir, lamivudine had been added to adefovir for treating resistance to adefovir. However, the antiviral response was not good when there was prior history of resistance to lamivudine. ${ }^{61}$ So it was considered inappropriate to combine drugs already developed resistance, ${ }^{61}$ as the antiviral resistance mutations may coexist on the same viral genome resulting in a remarkable decrease of susceptibility to the combination. Entecavir, which belongs to cyclopentane, does not share cross resistance with adefovir; ${ }^{59}$ adefovir resistant mutants such as rtA181T/V and rtN236T are sensitive to entecavir. ${ }^{22,62}$ However, the presence of lamivudine resistant mutations also limits its efficacy. ${ }^{63}$ Although initial antiviral response of entecavir was better than lamivudine plus adefovir in patients resistant to lamivudine and adefovir, ${ }^{64,65}$ the efficacy of entecavir was limited by high incidence of entecavir resistance during the long term treatment. ${ }^{66,67}$ Therefore, entecavir should not be used alone for the treatment of CHB resistant to both lamivudine and adefovir, and combination of adefovir and entecavir would be a more relevant choice. ${ }^{51,68}$

L-nucleoside analogues such as lamivudine or telbivudine may be added for the treatment of adefovir resistance developed in
CHB patients who have never been exposed to nucleoside analogues. However, in the presence of rtA181T mutation, this option is not appropriate due cross resistance to L-nucleoside analogues. ${ }^{59}$ Switching to entecavir in these patients could be considered, ${ }^{2}$ but long term safety of entecavir monotherapy has not been studied. So combining entecavir and adefovir would be a better option for the prevention of multidrug resistance as most guidelines recommend. ${ }^{1,3,4}$

Entecavir resistance; additional mutations on the background of lamivudine resistance

Resistance to entecavir can be managed by either tenofovir or adefovir based therapies.

- Preferred options for the treatment of entecavir resistance 1) rtL180M+rtM204V/I+rtT184L/F/A/M/S/I/C/G or rtS202G/I/C or rtM250V mutations

- Tenofovir plus one of nucleoside analogues

- Tenofovir monotherapy

- Adefovir plus entecavir

Entecavir resistance is rare in treatment naive patients. ${ }^{16} \mathrm{Al}$ though it is reported only approximately $1 \%$ of the subjects in the phase 3 studies, $^{16}$ patients with high baseline viral load and detectable HBV DNA after 12 months of treatment are at increased risk of resistance. ${ }^{69}$ Entecavir resistance is much more common in lamivudine refractory patients over $50 \%$ after 5 years of treatment. Although entecavir resistance may be considered as multidrug resistance in a broad concept, it is resistant only to nucleoside analogues, not to nucleotide analogues. So, all these mutations are susceptible to tenofovir, which is a potent antiviral drug. Long term efficacy of tenofovir monotherapy for CHB patients after failure of nucleos(t)ide analogues has been evaluated, but the number of subjects with entecavir resistance were too small to reach a conclusion in the retrospective cohort study conducted in Germany. ${ }^{39}$ Anyhow, the response was good to achieve virologic response within 12 weeks of treatment in a patient with rtL180M+rtM204V+rtS202G. ${ }^{39}$ Efficacy of tenofovir plus entecavir was evaluated in an international multicenter study. ${ }^{60}$ All four patients with entecavir resistant mutations achieved virologic response before 12 month of treatment. It is thought that tenofovir based therapies are effective in treating entecavir resistant CHB. Recent EASL guidelines recommend switching to or adding tenofovir as an initial option while APASL and KASL guidelines recommend adding tenofovir. ${ }^{1,2,4}$ 
During the pre-era of tenofovir, treatment of entecavir resistance was based on adefovir. A multicenter study conducted a prospective evaluation of combination of adefovir and lamivudine for entecavir resistance. ${ }^{70}$ The virologic response rate (HBV DNA $<20 \mathrm{IU} / \mathrm{mL}$ ) was only $23.5 \%$ after 12 months of treatment. However the entecavir resistant mutations disappeared or their proportion decreased in $62.6 \%$ of HBV-detectable patients. For entecavir resistance, combination of adefovir and entecavir seems to be a more potent treatment. A small retrospective single center study which included 12 entecavir resistant CHB patients reported virologic response rate of adefovir plus entecavir as $33.3 \%$ at 12 months and $50.0 \%$ at 18 months of treatment. ${ }^{71}$ Comparison of efficacy between adefovir plus lamivudine and adefovir plus entecavir for entecavir resistance was performed previously, but significant difference was not found. ${ }^{72}$ More recently, a multicenter retrospective study in Korea showed that HBV DNA suppression was more profound in the adefovir plus entecavir group compared with adefovir plus lamivudine group (-3.06 vs $-2.73 \mathrm{log} \mathrm{IU} / \mathrm{mL}$, $P=0.006)$ Therefore, adefovir plus entecavir would be a better choice, especially where tenofovir is not available.

Lamivudine, adefovir and entecavir resistance; a real multidrug resistance

Resistance to both nucleoside and nucleotide analogues can be developed after exposure to a single drug or more than two drugs; management should be done according to the resistance profile. If resistant mutations to adefovir and entecavir are found at the same time, the following is recommended.

- Preferred options for the treatment of resistance to lamivudine, adefovir and entecavir

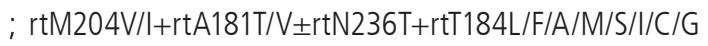
or rtS202G///C or rtM250V mutations

- Tenofovir plus entecavir

Multiple mutations causing resistance to both adefovir and entecavir are still not common, but it is difficult to manage once such mutations develop. Previously, adefovir plus entecavir combination was retrospectively evaluated for CHB patients after multiple failures of nucleos $(t)$ ide analogues. The rate of virologic response was only $14.3 \%$ of 35 patients who failed in 3 lines of antiviral therapy including lamivudine, adefovir, and entecavir treatment. ${ }^{73}$ Therefore, combination of adefovir and entecavir is considered suboptimal for this kind of difficult-to-treat patients. Tenofovir based therapy has been evaluated in a recent retrospective study. ${ }^{74}$ They included 18 patients who had failed treatment with entecavir, adefovir, and lamivudine. Seventeen patients achieved virologic response (HBV DNA < $60 \mathrm{IU} / \mathrm{mL}$ ) with tenofovir, tenofovir plus lamivudine, or tenofovir plus entecavir. One patient who did not achieve virologic response had received tenofovir monotherapy for 24 month. ${ }^{74}$ An international multicenter study which evaluated efficacy of tenofovir plus entecavir combination in various pretreated CHB patients included only one patient exhibiting resistance to lamivudine, adefovir, and entecavir at the same time. ${ }^{60}$ The patient responded to the combination after 9 months of therapy. Therefore, for patients with resistance to multiple lines of antiviral drugs, tenofovir based therapy is recommended preferably with entecavir. Long term efficacy and safety of this combination still need to be further evaluated.

\section{Tenofovir resistance; yet to be confirmed}

Although rtA194T mutation, which confers resistance to tenofovir, was found in HIV-HBV coinfected patients, ${ }^{26}$ tenofovir resistance has not been reported in HBV monoinfected patients so far. ${ }^{75}$ If tenofovir resistance is suspected, sequencing analysis and in vitro susceptibility tests need to be done to confirm genotypic and phenotypic resistance. ${ }^{28}$ Previous in vitro study showed that rtA194T mutant was susceptible to entecavir and telbivudine ${ }^{76}$ so adding these drugs would be effective. However, management should be stratified according to the result of the resistance test.

- Preferred options for the treatment of resistance to tenofovir ; rtA194T mutation

- Tenofovir plus entecavir

- Tenofovir plus telbivudine

\section{Prevention}

To prevent development of antiviral resistance, selection of appropriate patients is mandatory. The efficacy of antiviral treatment is not satisfactory in HBV carriers of the immune tolerant phase, and the risk of antiviral resistance increases. When pretreatment evaluation suggests antiviral therapy is necessary, potent drugs with high genetic barrier need to be implemented. Alternatively, peginterferon therapy should be considered in young patients with well preserved hepatic function, patients not eligible for long term therapies, and women considering pregnancy $1-2$ years later.

Once therapy has been initiated, time appropriate modification according to the response is needed to prevent development of future antiviral resistance. Recently, KASL guidelines suggest that 
Hyung Joon Yim, et al.

Options for the management of antiviral resistance during hepatitis B therapy

therapy should be changed in case of primary treatment failures, which is defined as a decrease of HBV DNA less than $2 \mathrm{log} \mathrm{IU} / \mathrm{mL}$ compared with baseline after 6 months of therapy. ${ }^{1}$ Before concluding primary non-response, drug compliance should be ensured, and antiviral resistance testing may be required. When changing the antiviral agent, drugs without cross resistance would be better, even though there are no confirmed mutations. For example, adefovir primary non-responders should change medication to entecavir preferably although tenofovir has been reported effective for the adefovir experienced patients. ${ }^{77}$ Primary non-responders to lamivudine may change to tenofovir.

Management of partial virologic response, which is defined by detectable HBV DNA after 6 to 12 months of therapy, should be stratified according to the drug being administered. Low genetic barrier drugs such as L-nucleoside analogues and adefovir need to be decided to change or not at 6 months of therapy. ${ }^{1}$ Potent antiviral drugs with high genetic barrier and no cross resistance are needed to be selected for substitution; tenofovir for L-nucleoside analogues and entecavir for adefovir would be preferred. If patient is taking a high genetic barrier drug, treatment can be continued for 12 months. If partial virologic response to entecavir is observed at month 12 and the patient had high baseline viral load (i.e. HBV DNA >8-9 $\log \mathrm{IU} / \mathrm{mL}$ ), long term antiviral response may not be satisfactory and subsequent risk of entecavir resistance increases. ${ }^{69,78}$ Also, if HBV DNA is over $1,000 \mathrm{lU} / \mathrm{mL}$ at month 12 , long term probability of virologic response is relatively lower. ${ }^{79}$ These patients would get benefit by switching to tenofovir. ${ }^{80,81}$ Partial virologic responders to tenofovir has been managed by adding emtricitabine at the discretion of investigator after 72 weeks of monotherapy in phase 3 trials. $^{27}$ The reason why tenofovir resistance has not been reported and the patients achieved high rate of virologic response may be attributed to this strategy. ${ }^{27}$ As emtricitabine has not been approved for HBV therapy, addition of other L-nucleoside analogues such as lamivudine, would be a relevant choice.

- Preferred options for partial virologic responders to prevent future resistance

1) In patients receiving L-nucleoside analogues

- Switch to tenofovir at week 24

2) In patients receiving adefovir

- Switch to entecavir at week 24

3) In patients receiving entecavir
- Continue entecavir

- Consider switch to tenofovir if high HBV DNA (i.e. >8 log

$\mathrm{IU} / \mathrm{mL}$ ) at baseline or HBV DNA $>3 \log \mathrm{IU} / \mathrm{mL}$ at week 48

4) In patients receiving tenofovir

- Continue tenofovir

- Consider adding one of L-nucleoside analogues at week 72

\section{CONCLUSIONS}

The selection of the antiviral resistant mutant is the process of "selection of the fittest under the pressure exerted by antiviral agent." ${ }^{11}$ Given that spontaneous error rates of HBV are high, a potent antiviral agent with high genetic barrier may mitigate the possibility of developing resistance. ${ }^{16,27}$ With the advancement of antiviral agents, the incidence of antiviral resistance is decreasing. However, a number of CHB patients who have been on treatment already developed antiviral resistance, and they are at risk of multidrug resistance. The golden time should not be missed to prevent this jeopardy. We expect future eradication of chronic HBV infection by proper prevention and management of antiviral resistance.

\section{Acknowledgements}

Sang Jun Suh and Sun Young Yim assisted in preparation of the manuscript. The authors thank members of Antiviral Resistance Study Group for responding to surveys on managing multidrug resistance; Hyoung Su Kim, Myoung Kuk Jang, Sang Jun Suh, Eileen Yoon, Yeon Seok Seo, Sun Young Yim, Ji Hoon Kim, Bo Hyun Kim, Sang Jong Park, Sae Hwan Lee, Sang Gyun Kim, Young Seok Kim, Jun Yong Park, Sang Hoon Ahn, Jeong II Lee, Jin Woo Lee, In Hee Kim, Tae Yeob Kim, Jin Wook Kim, Sook Hyang Jeong, Young Kul Jung, Hana Park, Eun Young Cho, Sun Pyo Hong, Soon Ho Um.

This article was funded partly by The Korean Association for the Study of the Liver research grant and partly by a grant of the Korea Healthcare technology R\&D Project, Ministry of Health and Welfare, Korea (HI10C2020).

\section{Conflicts of Interest}

The authors have no conflicts to disclose. 


\section{REFERENCES}

1. Korean Association for the Study of the Liver. KASL Clinical Practice Guidelines: Management of chronic hepatitis B. Clin Mol Hepatol 2012;18:109-162.

2. European Association For The Study Of The Liver. EASL clinical practice guidelines: Management of chronic hepatitis B virus infection. J Hepatol 2012;57:167-185.

3. Lok AS, McMahon BJ. Chronic hepatitis B: update 2009. Hepatology 2009;50:661-662.

4. Liaw YF, Kao JH, Piratvisuth T, Chan HLY, Chien RN, Liu CJ, et al. Asian-Pacific consensus statement on the management of chronic hepatitis B: a 2012 update. Hepatol Int 2012;6:531-561.

5. Ahn SH, Chan HL, Chen PJ, Cheng J, Goenka MK, Hou J, et al. Chronic hepatitis B: whom to treat and for how long? Propositions, challenges, and future directions. Hepatol Int 2010;4:386-395.

6. Yim HJ. Management of antiviral-resistant chronic hepatitis B virus infection. Korean J Gastroenterol 2008;51:346-359.

7. Yim HJ, Hussain M, Liu Y, Wong SN, Fung SK, Lok AS. Evolution of multi-drug resistant hepatitis B virus during sequential therapy. Hepatology 2006;44:703-712.

8. Nowak MA, Bonhoeffer S, Hill AM, Boehme R, Thomas HC, MCDade $H$. Viral dynamics in hepatitis B virus infection. Proc Natl Acad Sci U S A 1996;93:4398-4402.

9. Locarnini S, Mason WS. Cellular and virological mechanisms of HBV drug resistance. J Hepatol 2006;44:422-431.

10. Kim do Y, Chang HY, Lim SM, Kim SU, Park JY, Kim JK, et al. Quasispecies and pre-existing drug-resistant mutations of hepatitis $B$ virus in patients with chronic hepatitis B. Gut Liver 2013;7:329-334.

11. Richman DD. The impact of drug resistance on the effectiveness of chemotherapy for chronic hepatitis B. Hepatology 2000;32:866867.

12. Melegari M, Scaglioni PP, Wands JR. Hepatitis B virus mutants associated with 3TC and famciclovir administration are replication defective. Hepatology 1998;27:628-633.

13. Locarnini S, Warner N. Major causes of antiviral drug resistance and implications for treatment of hepatitis $B$ virus monoinfection and coinfection with HIV. Antivir Ther 2007;12(Suppl 3):H15-H23.

14. Richman DD. The implications of drug resistance for strategies of combination antiviral chemotherapy. Antiviral Res 1996;29:31-33.

15. Zoulim F. Mechanism of viral persistence and resistance to nucleoside and nucleotide analogs in chronic hepatitis B virus infection. Antiviral Res 2004;64:1-15.

16. Tenney DJ, Rose RE, Baldick CJ, Pokornowski KA, Eggers BJ, Fang $J$, et al. Long-term monitoring shows hepatitis $B$ virus resistance to entecavir in nucleoside-naive patients is rare through 5 years of therapy. Hepatology 2009;49:1503-1514.

17. Rapti I, Dimou E, Mitsoula P, Hadziyannis SJ. Adding-on versus switching-to adefovir therapy in lamivudine-resistant HBeAgnegative chronic hepatitis B. Hepatology 2007;45:307-313.

18. Zhang YY, Summers J. Enrichment of a precore-minus mutant of duck hepatitis B virus in experimental mixed infections. J Virol 1999;73:3616-3622.

19. Seeger C, Mason WS. Hepatitis B virus biology. Microbiol Mol Biol Rev 2000;64:51-68.

20. Yim HJ. Hepatitis B virus genetic diversity and mutant. Korean J Hepatol 2008;14:446-464.

21. Koh KH, Kang CJ, Kim DH, Choi YW, Kim MJ, Cheong JY, et al. Development of clevudine resistance after switching from lamivudine in a patient with chronic hepatitis B. Korean J Gastroenterol 2008;52:325-328.

22. Villet S, Pichoud C, Billioud G, Barraud L, Durantel S, Trepo C, et al. Impact of hepatitis B virus rtA181V/T mutants on hepatitis B treatment failure. J Hepatol 2008;48:747-755.

23. Tenney DJ, Levine SM, Rose RE, Walsh AW, Weinheimer SP, Discotto $L$, et al. Clinical emergence of entecavir-resistant hepatitis $B$ virus requires additional substitutions in virus already resistant to Lamivudine. Antimicrob Agents Chemother 2004;48:3498-3507.

24. Lee HW, Kim HJ, Hong SP, Cha BK, Chang HY, Choi CH, et al. Simultaneous emergence of entecavir resistance mutations in a nucleoside-naive chronic hepatitis B patient. Intervirology 2012;55:380384.

25. Angus $P$, Vaughan $R$, Xiong S, Yang H, Delaney W, Gibbs C, et al. Resistance to adefovir dipivoxil therapy associated with the selection of a novel mutation in the HBV polymerase. Gastroenterology 2003;125:292-297.

26. Sheldon J, Camino N, Rodes B, Bartholomeusz A, Kuiper M, Tacke $F$, et al. Selection of hepatitis $B$ virus polymerase mutations in HIV-coinfected patients treated with tenofovir. Antivir Ther 2005; 10:727-734.

27. Kitrinos KM, Corsa A, Liu Y, Flaherty J, Snow-Lampart A, Marcellin $P$, et al. No detectable resistance to tenofovir disoproxil fumarate after 6 years of therapy in patients with chronic hepatitis B. Hepatology. 2013 in print.

28. Lok AS, Zoulim F, Locarnini S, Bartholomeusz A, Ghany MG, Pawlotsky JM, et al. Antiviral drug-resistant HBV: standardization of nomenclature and assays and recommendations for management. Hepatology 2007;46:254-265.

29. Hongthanakorn C, Chotiyaputta W, Oberhelman K, Fontana RJ, Marrero JA, Licari $T$, et al. Virological breakthrough and resistance in patients with chronic hepatitis $B$ receiving nucleos(t)ide analogues in clinical practice. Hepatology 2011;53:1854-1863.

30. Stuyver L, Van Geyt C, De Gendt S, Van Reybroeck G, Zoulim F, Leroux-Roels $G$, et al. Line probe assay for monitoring drug resistance in hepatitis B virus-infected patients during antiviral therapy. J Clin Microbiol 2000;38:702-707. 
Hyung Joon Yim, et al. Options for the management of antiviral resistance during hepatitis B therapy

31. Hong SP, Kim NK, Hwang SG, Chung HJ, Kim S, Han JH, et al. Detection of hepatitis $B$ virus YMDD variants using mass spectrometric analysis of oligonucleotide fragments. J Hepatol 2004;40:837-844.

32. Yeon JE. Technique for the early detection of drug-resistant HBV DNA during antiviral therapy. Intervirology 2008;51(Suppl 1):7-10.

33. Solmone M, Vincenti D, Prosperi MC, Bruselles A, Ippolito G, Capobianchi MR. Use of massively parallel ultradeep pyrosequencing to characterize the genetic diversity of hepatitis B virus in drug-resistant and drug-naive patients and to detect minor variants in reverse transcriptase and hepatitis B S antigen. J Virol 2009;83:1718-1726.

34. Sun J, Hou JL, Xie Q, Li XH, Zhang JM, Wang YM, et al. Randomised clinical trial: efficacy of peginterferon alfa-2a in $\mathrm{HBeAg}$ positive chronic hepatitis B patients with lamivudine resistance. Aliment Pharmacol Ther 2011;34:424-431.

35. Chae HB, Hann HW. Baseline HBV DNA level is the most important factor associated with virologic breakthrough in chronic hepatitis B treated with lamivudine. World J Gastroenterol 2007;13:40854090.

36. Baran B, Soyer OM, Ormeci AC, Gokturk S, Evirgen S, Bozbey HU, et al. Efficacy of tenofovir in patients with Lamivudine failure is not different from that in nucleoside/nucleotide analogue-naive patients with chronic hepatitis B. Antimicrob Agents Chemother 2013:57:1790-1796.

37. van Bommel F, Wunsche T, Mauss S, Reinke P, Bergk A, Schurmann $D$, et al. Comparison of adefovir and tenofovir in the treatment of lamivudine-resistant hepatitis B virus infection. Hepatology 2004;40:1421-1425.

38. van Bommel F, Zollner B, Sarrazin C, Spengler U, Huppe D, Moller $B$, et al. Tenofovir for patients with lamivudine-resistant hepatitis $B$ virus (HBV) infection and high HBV DNA level during adefovir therapy. Hepatology 2006;44:318-325.

39. van Bommel F, de Man RA, Wedemeyer H, Deterding K, Petersen J, Buggisch $P$, et al. Long-term efficacy of tenofovir monotherapy for hepatitis B virus-monoinfected patients after failure of nucleoside/ nucleotide analogues. Hepatology 2010;51:73-80.

40. Fung $S$, Kwan P, Fabri MJ, Horban A, Pelemis M, Husa P, et al. Efficacy and safety of tenofovir DF (TDF) in chronic hepatitis $B$ virus infected patients with documented lamivudine resistance (LAM-R). [Abstract]. Hepatology 2012;56(Suppl):200A.

41. Patel N, Amarapurkar D. Tenofovir rescue therapy for patients with viral resistance to lamivudine and/or adefovir treatment. [Abstract]. Hep Intl 2010;4(Suppl1):161.

42. Wang Y, Thongsawat S, Gane EJ, Liaw YF, Jia J, Hou J, et al. Efficacy and safety of continuous 4-year telbivudine treatment in patients with chronic hepatitis B. J Viral Hepat 2013;20:e37-e46.

43. Lee YS, Suh DJ, Lim YS, Jung SW, Kim KM, Lee HC, et al. Increased risk of adefovir resistance in patients with lamivudine-resistant chronic hepatitis $B$ after 48 weeks of adefovir dipivoxil monothera- py. Hepatology 2006;43:1385-1391.

44. Yeon JE, Yoo W, Hong SP, Chang YJ, Yu SK, Kim JH, et al. Resistance to adefovir dipivoxil in lamivudine resistant chronic hepatitis B patients treated with adefovir dipivoxil. Gut 2006;55:1488-1495.

45. Ahn SH, Kweon YO, Paik SW, Sohn JH, Lee KS, Kim DJ, et al. Telbivudine in combination with adefovir versus adefovir monotherapy in HBeAg-positive, lamivudine-resistant chronic hepatitis B. Hepatol Int 2011 Oct 12. [Epub ahead of print].

46. Sherman M, Yurdaydin C, Sollano J, Silva M, Liaw YF, Cianciara J, et al. Entecavir for treatment of lamivudine-refractory, HBeAg-positive chronic hepatitis B. Gastroenterology 2006;130:2039-2049.

47. Chang TT, Gish RG, Hadziyannis SJ, Cianciara J, Rizzetto M, Schiff $E R$, et al. A dose-ranging study of the efficacy and tolerability of entecavir in Lamivudine-refractory chronic hepatitis B patients. Gastroenterology 2005;129:1198-1209.

48. Yim HJ, Seo YS, Yoon EL, Kim CW, Lee CD, Park SH, et al. Adding adefovir vs. switching to entecavir for lamivudine-resistant chronic hepatitis B (ACE study): a 2-year follow-up randomized controlled trial. Liver Int 2013;33:244-254.

49. Heo J, Ahn SH, Kweon YO, Kim BH, Chan HL, Horban A, et al. Entecavir+adefovir versus lamivudine+adefovir or entecavir alone in lamivudine-resistnat chronic hepatitis B: 96-week data from the define study. [Abstract]. In: The Korean Association for the Study of the Liver, ed. Abstracts of the 18th Annual Meeting of The Korean Association for the Study of the Liver. Seoul: The Korean Association for the Study of the Liver, 2012:4.

50. Lim YS, Lee JY, Lee D, Shim JH, Lee HC, Lee YS, et al. Randomized trial of entecavir plus adefovir in patients with lamivudine-resistant chronic hepatitis B who show suboptimal response to lamivudine plus adefovir. Antimicrob Agents Chemother 2012;56:2941-2947.

51. Chae HB, Kim MJ, Seo EG, Choi YH, Lee HS, Han JH, et al. High efficacy of adefovir and entecavir combination therapy in patients with nucleoside-refractory hepatitis B. Korean J Hepatol 2012;18:75-83.

52. Liaw YF, Gane E, Leung N, Zeuzem S, Wang Y, Lai CL, et al. 2-Year GLOBE trial results: telbivudine Is superior to lamivudine in patients with chronic hepatitis B. Gastroenterology 2009;136:486-495.

53. Zhang Y, Lian JQ, Li Y, Wang JP, Huang CX, Bai XF, et al. Telbivudine plus adefovir therapy for chronic hepatitis $B$ patients with virological breakthrough or genotypic resistance to telbivudine. Eur J Gastroenterol Hepatol 2013;25:814-819.

54. Xu XH, Li GL, Qin Y, Li Q, He FQ, Li JY, et al. Entecavir plus adefovir rescue therapy for chronic hepatitis $B$ patients after multiple treatment failures in real-life practice. Virol J 2013;10:162.

55. Cho EY, Yim HJ, Hwang SG, Kim JH, Seo YS, Kim JH, et al. Optimal management of clevudine resistant chronic hepatitis $B$; A multicenter retrospective study. [Abstract]. Korean J Hepatol 2010;16(Suppl 3):S46.

56. Berg T, Marcellin P, Zoulim F, Moller B, Trinh H, Chan S, et al. Te- 
nofovir is effective alone or with emtricitabine in adefovir-treated patients with chronic-hepatitis B virus infection. Gastroenterology 2010;139:1207-1217.

57. Patterson SJ, George J, Strasser SI, Lee AU, Sievert W, Nicoll AJ, et al. Tenofovir disoproxil fumarate rescue therapy following failure of both lamivudine and adefovir dipivoxil in chronic hepatitis B. Gut 2011;60:247-254

58. van Bommel F, Trojan J, Deterding K, Wedemeyer H, Wasmuth HE, Huppe $D$, et al. Evolution of adefovir-resistant HBV polymerase gene variants after switching to tenofovir disoproxil fumarate monotherapy. Antivir Ther 2012;17:1049-1058.

59. Qi X, Xiong S, Yang H, Miller M, Delaney WE 4th. In vitro susceptibility of adefovir-associated hepatitis $B$ virus polymerase mutations to other antiviral agents. Antivir Ther 2007;12:355-362.

60. Petersen J, Ratziu V, Buti M, Janssen HL, Brown A, Lampertico P, et al. Entecavir plus tenofovir combination as rescue therapy in pretreated chronic hepatitis B patients: an international multicenter cohort study. J Hepatol 2012;56:520-526.

61. Brunelle MN, Jacquard AC, Pichoud C, Durantel D, Carrouee-Durantel S, Villeneuve JP, et al. Susceptibility to antivirals of a human HBV strain with mutations conferring resistance to both lamivudine and adefovir. Hepatology 2005;41:1391-1398.

62. Shim JH, Suh DJ, Kim KM, Lim YS, Lee HC, Chung YH, et al. Efficacy of entecavir in patients with chronic hepatitis $B$ resistant to both lamivudine and adefovir or to lamivudine alone. Hepatology 2009;50:1064-1071.

63. Cho SW, Koh KH, Cheong JY, Lee MH, Hong SP, Yoo WD, et al. Low efficacy of entecavir therapy in adefovir-refractory hepatitis $\mathrm{B}$ patients with prior lamivudine resistance. J Viral Hepat 2010;17:171177.

64. Son CY, Ryu HJ, Lee JM, Ahn SH, Kim do Y, Lee MH, et al. Lamivudine plus adefovir vs. entecavir in HBeAg-positive hepatitis B with sequential treatment failure of lamivudine and adefovir. Liver Int 2012;32:1179-1185.

65. Heo NY, Lim YS, Lee HC, Chung YH, Lee YS, Suh DJ. Lamivudine plus adefovir or entecavir for patients with chronic hepatitis $B$ resistant to lamivudine and adefovir. J Hepatol 2010;53:449-454.

66. Park JW, Kim HS, Seo DD, Jang JS, Shin WG, Kim KH, et al. Longterm efficacy of entecavir in adefovir-refractory chronic hepatitis B patients with prior lamivudine resistance. J Viral Hepat 2011;18:e475-e481.

67. Kwak MS, Choi JW, Lee JS, Kim KA, Suh JH, Cho YS, et al. Longterm efficacy of entecavir therapy in chronic hepatitis $B$ patients with antiviral resistance to lamivudine and adefovir. J Viral Hepat 2011;18:e432-e438.

68. Park MS, Kim BK, Kim KS, Kim JK, Kim SU, Park JY, et al. Antiviral efficacies of currently available rescue therapies for multidrugresistant chronic hepatitis B. Clin Mol Hepatol 2013;19:29-35.
69. Kim HR, Yim HJ, Suh SJ, Lee HJ, Yoon EL, Kang SH, et al. Entecavir in patients with chronic hepatitis B with high viral load: Need of amendment in KASL guidelines. [Abstract]. In: The Korean Association for the Study of the Liver, ed. 2013 Abstracts of the 19th Annual Meeting of The Korean Association for the Study of the Liver. Seoul: The Korean Association for the Study of the Liver, 2013:58.

70. Yim HJ, Lee HJ, Um SH, Seo YS, Kim CW, Lee CD, et al. Adefovir and lamivudine combination therapy in patients with entecavir resistance (ALTER study). [Abstract]. Hepatology 2012;56(Suppl):393A.

71. Jeon JW, Shin HP, Lee JI, Joo KR, Cha JM, Park JJ, et al. Efficacy of entecavir and adefovir combination therapy for patients with lamivudine- and entecavir-resistant chronic hepatitis B. Dig Dis Sci 2012;57:1358-1365.

72. Kim SS, Cheong JY, Lee D, Lee MH, Hong SP, Kim SO, et al. Adefovir-based combination therapy with entecavir or lamivudine for patients with entecavir-refractory chronic hepatitis B. J Med Virol 2012;84:18-25.

73. Lim YS, Lee TH, Heo NY, Shim JH, Lee HC, Suh DJ. Entecavir plus adefovir combination treatment for chronic hepatitis B patients after failure of nucleoside/nucleotide analogues. Antivir Ther 2012;17:53-60.

74. Kim YJ, Sinn DH, Gwak GY, Choi MS, Koh KC, Paik SW, et al. Tenofovir rescue therapy for chronic hepatitis B patients after multiple treatment failures. World J Gastroenterol 2012;18:6996-7002.

75. Marcellin P, Gane E, Buti M, Afdhal N, Sievert W, Jacobson IM, et al. Regression of cirrhosis during treatment with tenofovir disoproxil fumarate for chronic hepatitis B: a 5-year open-label follow-up study. Lancet 2013;381:468-475.

76. Amini-Bavil-Olyaee S, Herbers U, Sheldon J, Luedde T, Trautwein C, Tacke $F$. The rtA194T polymerase mutation impacts viral replication and susceptibility to tenofovir in hepatitis B e antigen-positive and hepatitis B e antigen-negative hepatitis B virus strains. Hepatology 2009:49:1158-1165.

77. Tan J, Degertekin B, Wong SN, Husain M, Oberhelman K, Lok AS. Tenofovir monotherapy is effective in hepatitis B patients with antiviral treatment failure to adefovir in the absence of adefovirresistant mutations. J Hepatol 2008;48:391-398.

78. Tong H, Yan LB, Chen EQ, Yang WB, Du LY. The efficacy of entecavir treatment for up to 96 weeks in $\mathrm{HBeAg}$ postivie chronic hepatitis B patients with high viral load. [Abstract]. Hepatology 2012;56(Suppl):409A.

79. Zoutendijk R, Reijnders JG, Brown A, Zoulim F, Mutimer D, Deterding $\mathrm{K}$, et al. Entecavir treatment for chronic hepatitis $\mathrm{B}$ : adaptation is not needed for the majority of naive patients with a partial virological response. Hepatology 2011;54:443-451.

80. Yip B, Chaung K, Wong CR, Trinh HN, Nguyen HA, Ahmed A, et al. Tenofovir monotherapy and tenofovir plus entecavir combination as rescue therapy for entecavir partial responders. Dig Dis Sci 
Hyung Joon Yim, et al. Options for the management of antiviral resistance during hepatitis B therapy

2012; 57:3011-3016.

81. Pan CQ, Hu KQ, Yu AS, Chen W, Bunchorntavakul C, Reddy KR. Response to tenofovir monotherapy in chronic hepatitis $B$ pa- tients with prior suboptimal response to entecavir. J Viral Hepat 2012;19:213-219. 